\title{
Evaluation of combinations of nisin, lauric arginate, and $\varepsilon$-polylysine to control Listeria monocytogenes in queso fresco
}

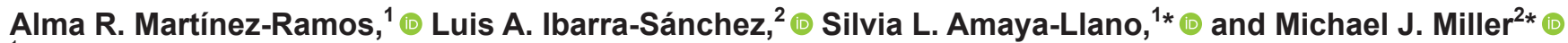 \\ ${ }^{1}$ Posgrado de Alimentos de la Facultad de Química, Universidad Autónoma de Querétaro, Querétaro, QRO, México 76010 \\ ${ }^{2}$ Department of Food Science and Human Nutrition, University of Illinois, Urbana 61801
}

\begin{abstract}
Listeria monocytogenes contamination is of great concern in queso fresco $(\mathrm{QF})$, and listeriosis outbreaks linked to consumption of QF continue to happen. Hurdle approaches such as combining antimicrobials provide an alternative to improve QF safety. In this work, the efficacy of antimicrobial combinations of nisin (NIS), lauric arginate (LAE), and $\varepsilon$-polylysine (EPL) to inhibit L. monocytogenes growth in QF was evaluated. First, antimicrobials were screened for potential synergy in vitro. Later, antimicrobial treatments were challenged in QF inoculated with $\sim 4 \log _{10} \mathrm{cfu} / \mathrm{g}$ of $L$. monocytogenes 5-strain cocktail and stored for $28 \mathrm{~d}$ at $4^{\circ} \mathrm{C}$. Our results showed that combinations of NIS-LAE and EPL-LAE were synergistic in vitro. Limited antilisterial control was observed in QF treated with NIS, LAE, and NIS-LAE; however, EPL and EPL-LAE exhibited listeristatic effect in QF for up to 14 and $28 \mathrm{~d}$ of cold storage, respectively. Additionally, L. monocytogenes QF isolates had similar susceptibility to EPL or LAE. A consumer panel was able to distinguish between QF added with EPL $(250 \mu \mathrm{g} / \mathrm{g})+\mathrm{LAE}(66.66 \mu \mathrm{g} / \mathrm{g})$ and control QF, most likely associated with manufacturing and storage rather than antimicrobials' taste. Our results support the use of EPL-LAE combination to control L. monocytogenes growth in QF.
\end{abstract}

Key words: nisin, lauric arginate, $\varepsilon$-polylysine, Listeria monocytogenes, queso fresco

\section{INTRODUCTION}

Listeria monocytogenes, a zero-tolerance foodborne pathogen, is among the leading causes of death from foodborne diseases and is responsible for estimated economic losses of $>\$ 2.8$ billion annually in the United

Received June 2, 2020.

Accepted August 1, 2020.

*Corresponding authors: samayal@uaq.mx and mille216@illinois .edu
States (Hoffmann et al., 2012; USDA ERS, 2014). Listeria monocytogenes contamination is a serious public health concern in dairy products especially in Hispanicstyle cheeses, which are often involved in listeriosis outbreaks (CDC-NORS, 2018). Queso fresco (QF), the main Hispanic-style cheese produced in the United States, is known to provide favorable conditions for $L$. monocytogenes growth such as low acidity, high moisture, and low salt content (Ibarra-Sánchez et al., 2017).

Current research dedicated to improving QF safety have been oriented to the application of antimicrobial agents, especially those from natural sources or derived from food components. Nisin (NIS) is a cationic antimicrobial peptide produced by Lactococcus lactis ssp. lactis, and its efficacy against gram-positive bacteria such as L. monocytogenes is well documented (Liu and Hansen, 1990; Ibarra-Sánchez et al., 2020). However, the hydrophobic nature of NIS and instability at neutral $\mathrm{pH}$ limits its potential for use in QF, a whole-fat and near-neutral-pH food (Ibarra-Sánchez et al., 2020). Lauric arginate (LAE) is a cationic surfactant, synthesized from lauric acid and L-arginine, with a wide antimicrobial spectrum (Ma et al., 2020). Lauric arginate is odorless and colorless, and it is rapidly metabolized to its natural components (lauric acid and arginine), which makes LAE a promising food preservative (Hawkins et al., 2009; Becerril et al., 2013). A limited number of studies have investigated the antilisterial efficacy of $\mathrm{LAE}$ in $\mathrm{QF}$ and reported transient Listeria control in the cheese (Soni et al., 2010, 2012). $\varepsilon$-Polylysine (EPL) is another natural antimicrobial peptide that has been used as a food preservative. $\varepsilon$-Polylysine is a cationic homopolymer of L-lysine that contains approximately 30 lysine residues; is nontoxic, water soluble, and stable at high temperatures; and exhibits a wide antimicrobial spectrum (Hiraki et al., 2003; Tuersuntuoheti et al., 2019). $\varepsilon$-Polylysine is active in a wide range of $\mathrm{pH}$ $(4-7.5)$ and acts as a good bacteriostatic agent in foods that contain low amounts of protein (Tuersuntuoheti et al., 2019). To the best of our knowledge, EPL is poorly studied in QF and only one study has evaluated EPL in QF for L. monocytogenes control (Kozak et al., 2018). 
Table 1. Listeria strains used in this work

\begin{tabular}{lll}
\hline Listeria strain & Serotype & Isolation source \\
\hline Listeria innocua ATCC 33090 & $6 \mathrm{a}$ & Animal, cow brain \\
Listeria monocytogenes NRRL B-33104 & $4 \mathrm{~b}$ & Food, epidemic, Jalisco cheese \\
L. monocytogenes NRRL B-33513 & $4 \mathrm{~b}$ & Food, epidemic, pate \\
L. monocytogenes NRRL B-33420 & $4 \mathrm{~b}$ & Food, epidemic, meat products \\
L. monocytogenes NRRL B-33424 & $1 / 2 \mathrm{~b}$ & Human, epidemic, chocolate milk \\
L. monocytogenes NRRL B-33419 & $1 / 2 \mathrm{a}$ & Human, epidemic, sliced turkey \\
\hline
\end{tabular}

These antimicrobials, NIS, LAE, and EPL, are generally recognized as safe (GRAS) and approved for their use in foods in the United States at legal limits of 250, 200, and $250 \mathrm{mg} / \mathrm{kg}$, respectively (21CFR184.1538; FDA, 2004, 2005), whereas NIS and LAE at concentrations of 12.5 and $200 \mathrm{mg} / \mathrm{kg}$, respectively, are permitted for unripened cheeses by the Codex General Standards for Food Additives (GSFA, Codex STAN 192-1995).

Combinations of antimicrobials may improve food safety when limitations of the efficacy of individual antimicrobials in the food are found. Other advantages of applying antimicrobial combinations include the reduction of the antimicrobial concentrations, which may lower costs and limit sensory effect (David et al., 2013). Several publications have evaluated antimicrobial combinations in QF to control L. monocytogenes and Salmonella (Gadotti et al., 2014; Lourenço et al., 2017; Ibarra-Sánchez et al., 2018; Kozak et al., 2018; Gadotti et al., 2020). However, the antimicrobial combinations between NIS, LAE, and EPL have not been investigated in QF for their antilisterial efficacy under standard refrigeration conditions, and their possible effect on QF sensory properties. The objective of this study was to evaluate and identify effective antilisterial treatments using combinations of existing antimicrobials (NIS, LAE, and EPL) for their application in QF; additionally, the potential sensory effect of those antimicrobial treatments in QF was investigated.

\section{MATERIALS AND METHODS}

\section{Bacterial Strains and Growth Conditions}

Table 1 shows Listeria strains used in this study. Each strain was recovered from a glycerol stock at $-80^{\circ} \mathrm{C}$ and cultured in brain heart infusion broth (BHI; Difco, Becton Dickinson and Co., Sparks, MD) at $37^{\circ} \mathrm{C}$, with agitation of $250 \mathrm{rpm}$ for $24 \mathrm{~h}$ to obtain an inoculum of approximately $9 \log _{10} \mathrm{cfu} / \mathrm{mL}$. Dilutions were prepared using Listeria innocua or a cocktail of $5 \mathrm{~L}$. monocytogenes strains (listed in Table 1) to obtain an inoculum of $5 \log _{10} \mathrm{cfu} / \mathrm{mL}$ in double-concentrated BHI (microtiter plate experiments) or $4 \log _{10} \mathrm{cfu} / \mathrm{mL}$ in PBS $(\mathrm{KCl}$, $200 \mathrm{mg} / \mathrm{L} ; \mathrm{KH}_{2} \mathrm{PO}_{4}, 200 \mathrm{mg} / \mathrm{L} ; \mathrm{NaCl}, 8 \mathrm{~g} / \mathrm{L} ; \mathrm{Na}_{2} \mathrm{HPO}_{4}$,
$1.15 \mathrm{~g} / \mathrm{L}, \mathrm{pH}$ 7.2; QF experiments). Listeria enumeration was carried out by spread plating $100 \mu \mathrm{L}$ of serially diluted sample on PALCAM Listeria-Selective agar (EMD-Millipore, Burlington, MA) plates supplemented with $20 \mu \mathrm{g} / \mathrm{mL}$ ceftazidime (Tokyo Chemical Industry Co. Ltd., Tokyo, Japan) and incubated at $37^{\circ} \mathrm{C}$ for 48 h.

\section{Commercial GRAS Antimicrobials}

The antimicrobials used in this study were nisin (NIS, Nisaplin 2.5\% wt/wt, Danisco, New Century, KS), $\varepsilon$-polylysine (EPL, purity $>98 \%$, Wilshire Technologies, Princeton, NJ), and lauric arginate $(\mathbf{L A E}$, CytoGuard LA 20, 10\% wt/vol lauric arginate, kindly provided by A\&B Ingredients Inc., Fairfield, NJ). The antimicrobial stocks were prepared fresh with sterile deionized water and filter-sterilized (PES syringe filter $0.22 \mu \mathrm{m}$, Thermo Fisher Scientific, Waltham, MA) before their use.

\section{Determination of Minimum Inhibitory Concentration}

The minimum inhibitory concentration of each antimicrobial was determined via the broth dilution method as described by Van Tassell et al. (2015). Briefly, overnight cultures of Listeria strains were inoculated at approximately $5 \log _{10} \mathrm{cfu} / \mathrm{mL}$ into 96 -well microtiter plates containing wells with serial 2-fold dilutions of NIS, LAE, and EPL in BHI broth, starting from 1.6 $\mathrm{mg} / \mathrm{mL}$ for NIS and $2 \mathrm{mg} / \mathrm{mL}$ for LAE and EPL. Plates were prepared in triplicate and the MIC was defined as the lowest antimicrobial concentration that visibly prevented growth after overnight incubation at $37^{\circ} \mathrm{C}$.

\section{Checkerboard Assay to Study Antimicrobial Interactions}

The interaction between the antimicrobials was determined using the checkerboard synergy test (2-dimension microdilution method) according to García (2010) with modifications. The checkerboard assays were performed with 96-well sterile microtiter plates and serial dilutions of the binary combinations of GRAS antimicrobials: 
NIS-LAE, NIS-EPL, and LAE-EPL. For each combination, the first antimicrobial compound (A) was serially diluted in the horizontal rows, whereas the second antimicrobial compound (B) was diluted in the vertical columns. The antimicrobial concentrations ranged from the MIC value to 5 serial 2 -fold dilutions. For the purpose of identify binary combinations that potentially allow lowering the concentration of either antimicrobial in the mixture, concentrations above MIC value were not tested in the checkerboard method. Consequently, antagonistic effects, if any, could not be observed. The micro-broth dilution technique was performed as described above using BHI broth for ease comparison between MIC and checkerboard assays. Then fractional inhibitory concentration index (FIC) was calculated to characterize antimicrobial interactions as synergistic or additive by using the following equation:

$$
\mathrm{FIC}=\mathrm{FIC}_{\mathrm{A}}+\mathrm{FIC}_{\mathrm{B}},
$$

$\mathrm{FIC}=$

$\frac{\text { MIC of } \mathrm{A} \text { in combination }}{\text { MIC of A }}+\frac{\text { MIC of B in combination }}{\text { MIC of B }}$.

The classification of the antimicrobial interaction was made using the following parameters: when FIC $\leq 0.5$ the interaction is synergistic, and when $0.5<$ FIC $\leq$ 2.0 the interaction is additive.

\section{Evaluation of Antimicrobials in Miniaturized Laboratory QF}

Antimicrobial compounds were evaluated by their addition to miniaturized laboratory QF. Batches of QF were prepared using pasteurized whole milk as previously described with minor modifications (Van Tassell et al., 2015). Briefly, sample cheeses were inoculated with a 5 -strain $L$. monocytogenes cocktail directly into the curd before pressing, for a final inoculum of approximately $4 \log _{10} \mathrm{cfu} / \mathrm{g}$. In all batches, antimicrobials were incorporated into drained curd before pressing as follows: after inoculation and a 15-min incubation to allow Listeria to attach to the curds, tubes were centrifuged at $6,000 \times g$ for 5 min at room temperature $\left(25^{\circ} \mathrm{C}\right)$ for incomplete pressing. All accessible whey was removed, and antimicrobials were mixed with the curd at their maximum permissible concentration in the United States $(250 \mu \mathrm{g} / \mathrm{g}$ NIS, $200 \mu \mathrm{g} / \mathrm{g}$ LAE, and 250 $\mu \mathrm{g} / \mathrm{g}$ EPL). The following treatments were evaluated: control (no antimicrobial), single antimicrobials (NIS, LAE, and EPL), and binary combinations (NIS-LAE and LAE-EPL). The curd was centrifuged for another 8 min at $6,000 \times g$ at room temperature $\left(25^{\circ} \mathrm{C}\right)$, the remaining whey was removed and all cheese samples were stored at $4^{\circ} \mathrm{C}$ for up to $28 \mathrm{~d}$, until sampled. Listeria monocytogenes cells were enumerated by spread plating on PALCAM Listeria-Selective agar supplemented with $20 \mu \mathrm{g} / \mathrm{mL}$ ceftazidime. All treatments were evaluated in duplicate and the experiment was performed 3 times.

\section{Evaluation of Binary Combinations Between $L A E$ and $E P L$ in $Q F$}

From results obtained in the previous section, binary combinations with lower concentrations of LAE and EPL were evaluated in QF as described above. Two equidistant points between zero and the maximum permissible concentration of each antimicrobial were selected. The evaluated treatments are shown in Table 2. By the end of QF storage, 3 random L. monocytogenes isolates per cheese treatment (control, $250 \mu \mathrm{g} / \mathrm{g} \mathrm{EPL}$, $200 \mu \mathrm{g} / \mathrm{g} \mathrm{LAE}$, and $250 \mu \mathrm{g} / \mathrm{g}$ EPL $+200 \mu \mathrm{g} / \mathrm{g} \mathrm{LAE})$, per independent experiment, were recovered from PALCAM plates and cultured individually for antimicrobial susceptibility testing.

Table 2. Evaluated treatments with binary combinations from lauric arginate (LAE) and $\varepsilon$-polylysine (EPL) compounds

\begin{tabular}{|c|c|c|c|c|}
\hline \multirow[b]{2}{*}{ Treatment } & \multicolumn{2}{|c|}{ EPL } & \multicolumn{2}{|c|}{ LAE } \\
\hline & $\begin{array}{l}\text { Concentration } \\
(\mu \mathrm{g} / \mathrm{g})\end{array}$ & Proportion & $\begin{array}{c}\text { Concentration } \\
(\mu \mathrm{g} / \mathrm{g})\end{array}$ & Proportion \\
\hline A & - & - & - & - \\
\hline B & 250.00 & 1 & - & - \\
\hline $\mathrm{C}$ & - & - & 200.00 & 1 \\
\hline D & 250.00 & 1 & 200.00 & 1 \\
\hline $\mathrm{E}$ & 250.00 & 1 & 133.33 & $2 / 3$ \\
\hline $\mathrm{F}$ & 250.00 & 1 & 66.66 & $1 / 3$ \\
\hline G & 166.66 & $2 / 3$ & 200.00 & 1 \\
\hline $\mathrm{H}$ & 83.33 & $1 / 3$ & 200.00 & 1 \\
\hline
\end{tabular}




\section{Susceptibility Assessment of QF L. Monocytogenes Isolates to EPL and LAE}

Antimicrobial susceptibility of L. monocytogenes isolates from QF was assessed as described by IbarraSánchez et al. (2018) with minor modifications. A total of 36 random L. monocytogenes isolates (see above) were recovered from PALCAM plates from QF samples (control, $250 \mu \mathrm{g} / \mathrm{g}$ EPL, $200 \mu \mathrm{g} / \mathrm{g} \mathrm{LAE}$, and $250 \mu \mathrm{g} / \mathrm{g}$ $\mathrm{EPL}+200 \mu \mathrm{g} / \mathrm{g}$ LAE) immediately after the plate's incubation period, and single colonies were inoculated in BHI broth and incubated at $37^{\circ} \mathrm{C}$ for $24 \mathrm{~h}$. The antimicrobial susceptibility of $L$. monocytogenes isolates to EPL and LAE was determined by testing the MIC of each antimicrobial. Because no cutoff MIC values have been established for food antimicrobials (EPL and $\mathrm{LAE}$ ), MIC ranges of antimicrobial-treated QF isolates were compared against control QF isolates. Listeria monocytogenes community QF isolates were identified as less susceptible (resistant) when the community isolate MIC mean was significantly different from the overall susceptibility in the population by the analysis of means (ANOM).

\section{Traditional-Scale Queso Fresco Production Added With LAE-EPL Mixture}

Queso fresco at traditional scale was produced using pasteurized whole milk as previously described with minor modifications (Van Tassell et al., 2015). Milk $(18.9 \mathrm{~L})$ was warmed at $35^{\circ} \mathrm{C}$; then, $4.15 \mathrm{~g}$ of $\mathrm{CaCl}_{2}$ and $8 \mathrm{~mL}$ of rennet (both diluted 1:10 in purified water) were added. The curd formed over $45 \mathrm{~min}$ and was then cut into small cubes. The curd was stirred for $10 \mathrm{~min}$ at the same temperature. A heating ramp was made to reach $40^{\circ} \mathrm{C}$ for $30 \mathrm{~min}$ increasing in $1^{\circ} \mathrm{C}$ every $6 \mathrm{~min}$. Two-thirds of the total whey was drained and $151.2 \mathrm{~g}$ of $\mathrm{NaCl}$ was added to the curds and stirred for $10 \mathrm{~min}$ at $40^{\circ} \mathrm{C}$. Subsequently, total draining whey was performed and the curd was separated into 2 parts; one was mixed with antimicrobial mixture (QFT: $250 \mu \mathrm{g} / \mathrm{g}$ EPL + $66.66 \mu \mathrm{g} / \mathrm{g} \mathrm{LAE})$ and the other was performed as described above without treatment (QFC). The curd was transferred to cheese molds and refrigerated at $4^{\circ} \mathrm{C}$ for $24 \mathrm{~h}$. After $24 \mathrm{~h}$, cheese was vacuum packed and stored at $4^{\circ} \mathrm{C}$.

\section{Sensory Evaluation: Triangle Test}

This evaluation was carried out to determine if EPLLAE addition may modify sensorial properties of cheese. In this way, a triangle test was performed according to ISO 4120 (2004) with the purpose of identifying if there is a similarity between QF samples added with (QFT) or without (QFC) EPL-LAE. Briefly, untrained panelists $(\mathrm{n}=64: \mathrm{d} 1 ; 29$ female and 35 male, d 15; 44 female and 22 male, 18-60 yr old) received a set of 3 samples and were informed that 2 samples were alike and that 1 was different. The samples were codified with 3 randomly generated numbers and presented to assessors in 6 different sequences. The assessors reported which sample they believed was different and assessors were asked to report their remarks, if any. The number of correct responses was counted, and the results were tested for similarity according to ISO 4120 (2004). The allowable proportion of discriminators chosen was $P d$ $=20 \%$ and $\beta=0.1$. The proportion of the population that can distinguish the samples $(\% P)$ was calculated as follows:

$$
\% P=\left\{[1.5(x / n)-0.5]+1.5 z \beta \sqrt{\left(n x-x^{2}\right) / n^{3}}\right\} 100,
$$

where $x$ is the number of correct answers, $n$ is the number of assessors, and $z \beta=1.28$ for $\beta=0.1$. When the computed value $(\% P)$ is less than the selected limit for $P d(20 \%)$, then samples are considered similar at the $\beta$ level of significance (ISO 4120, 2004). Triangle test was carried out at $\mathrm{d} 1$ and 15 of storage at $4^{\circ} \mathrm{C}$.

\section{Statistical Analysis}

All the experiments were performed independently 3 times with duplicate samples for each time point and the dilutions were plated in triplicate. Experiments were analyzed as completely randomized designs using JMP 13.1 (SAS Institute Inc., Cary, NC). The ANOVA was carried out to establish the significance of the factors, and the ANOM was applied to determine which of the L. monocytogenes community isolates from cheese exhibits antimicrobial susceptibility that is significantly different from the overall susceptibility in the population. The results were expressed as the mean \pm standard error.

\section{RESULTS}

\section{Determination of MIC and Checkerboard Assays}

The MIC of GRAS antimicrobials NIS, LAE, and EPL against L. innocua and L. monocytogenes in BHI broth are shown in Table 3. The MIC for NIS and LAE were up to $12.5 \mu \mathrm{g} / \mathrm{mL}$, whereas the MIC for EPL was $125 \mu \mathrm{g} / \mathrm{mL}$, which is half the maximum concentration allowed by the FDA $(250 \mu \mathrm{g} / \mathrm{g})$ and 10-fold higher 
Table 3. Minimum inhibitory concentration of generally recognized as safe antimicrobials ${ }^{1}$

\begin{tabular}{lccc}
\hline Listeria strain & $\begin{array}{c}\mathrm{NIS} \\
(\mu \mathrm{g} / \mathrm{mL})\end{array}$ & $\begin{array}{c}\mathrm{LAE} \\
(\mu \mathrm{g} / \mathrm{mL})\end{array}$ & $\begin{array}{c}\mathrm{EPL} \\
(\mu \mathrm{g} / \mathrm{mL})\end{array}$ \\
\hline Listeria innocua ATCC 33090 & 12.5 & 12.5 & 125 \\
Listeria monocytogenes NRRL B-33104 & 6.25 & 12.5 & 125 \\
L. monocytogenes NRRL B-33513 & 6.25 & 12.5 & 125 \\
L. monocytogenes NRRL B-33420 & 6.25 & 12.5 & 125 \\
L. monocytogenes NRRL B-33424 & 3.12 & 12.5 & 62.5 \\
L. monocytogenes NRRL B-33419 & 6.25 & 12.5 & 125 \\
\hline
\end{tabular}

${ }^{1} \mathrm{NIS}=$ nisin; LAE $=$ lauric arginate; $\mathrm{EPL}=\varepsilon$-polylysine.

than the MIC values for LAE and NIS. Additionally, L. monocytogenes strains were more susceptible to NIS (lower MIC values) than $L$. innocua.

To determine potential interactions between binary combinations of GRAS antimicrobials in broth, a checkerboard assay using L. innocua and L. monocytogenes NRRL B-33104 (isolated from epidemic Jalisco cheese) was performed. A synergistic interaction was observed for NIS-LAE and EPL-LAE against both L. innocua and L. monocytogenes, whereas NIS-EPL exhibited an additive effect against Listeria (Table 4). Only combinations that showed synergism were selected for further experiments.

\section{Evaluation of Antimicrobials Alone and in Combinations in QF}

Antimicrobial treatments evaluated in QF were selected based on the results obtained in checkerboard assays. Listeria monocytogenes reached approximately $9 \log _{10} \mathrm{cfu} / \mathrm{g}$ in untreated cheeses by d 28 of storage, an increase of approximately $5 \log _{10} \mathrm{cfu} / \mathrm{g}$ from the initial inoculum (Figure 1a). The EPL exhibited initially a listeristatic effect (bacteriostatic to Listeria), but subsequent regrowth of $L$. monocytogenes was observed after $14 \mathrm{~d}$ of cold storage. The NIS and LAE alone were the least effective treatments to inhibit L. monocytogenes growth in $\mathrm{QF}$, in which pathogen regrowth was observed from early cheese storage.
Binary combination of NIS-LAE did not show antilisterial improvement compared with those antimicrobials used individually. The mixture of EPL and LAE was effective in combination compared with using the antimicrobials separately. After $28 \mathrm{~d}$ of storage at $4^{\circ} \mathrm{C}$, L. monocytogenes population increased approximately $1.5 \log _{10} \mathrm{cfu} / \mathrm{g}$ from the initial inoculum, this was $\sim 3.5$ $\log _{10} \mathrm{cfu} / \mathrm{g}$ lower compared with control cheeses (Figure $1 b)$.

\section{Evaluation of Binary Combinations Between $L A E$ and $E P L$ in QF}

Partial optimization of the antimicrobial combination between EPL and LAE in QF was evaluated by reducing their concentrations: one antimicrobial was kept at their maximum permissible amount $(250 \mu \mathrm{g} / \mathrm{g}$ EPL, $200 \mu \mathrm{g} / \mathrm{g}$ LAE), whereas the concentration of the second antimicrobial was reduced according to Table 2. Cheeses treated with LAE and EPL alone were consistent with results in the previous cheese challenge: LAE did not reduce L. monocytogenes counts in QF, and EPL was listeristatic in QF for up to 2 wk of cold storage. In cheeses treated with the antimicrobial combination in which EPL was decreased, L. monocytogenes population reached approximately $7.5 \log _{10} \mathrm{cfu} / \mathrm{g}$ $\left(\sim 3 \log _{10} \mathrm{cfu} / \mathrm{g}\right.$ growth from the initial inoculum) by the end of the cheese storage, whereas $\sim 1.5 \log _{10} \mathrm{cfu} / \mathrm{g}$ growth of L. monocytogenes in QF with EPL-LAE at

Table 4. Interaction effect between generally recognized as safe antimicrobials in culture broth

\begin{tabular}{|c|c|c|c|c|}
\hline \multirow{2}{*}{$\begin{array}{l}\text { Antimicrobial } \\
\text { combination }^{1}\end{array}$} & \multicolumn{2}{|c|}{ Listeria innocua } & \multicolumn{2}{|c|}{$\begin{array}{l}\text { Listeria monocytogenes } \\
\text { NRRL B-33104 }\end{array}$} \\
\hline & FIC $^{2}$ & Effect & FIC & Effect \\
\hline LAE + NIS & $0.40 \pm 0.10$ & Synergistic & $0.50 \pm 0.14$ & Synergistic \\
\hline $\mathrm{EPL}+\mathrm{LAE}$ & $0.44 \pm 0.07$ & Synergistic & $0.34 \pm 0.09$ & Synergistic \\
\hline NIS + EPL & $1.33 \pm 0.33$ & Additive & $0.92 \pm 0.08$ & Additive \\
\hline
\end{tabular}



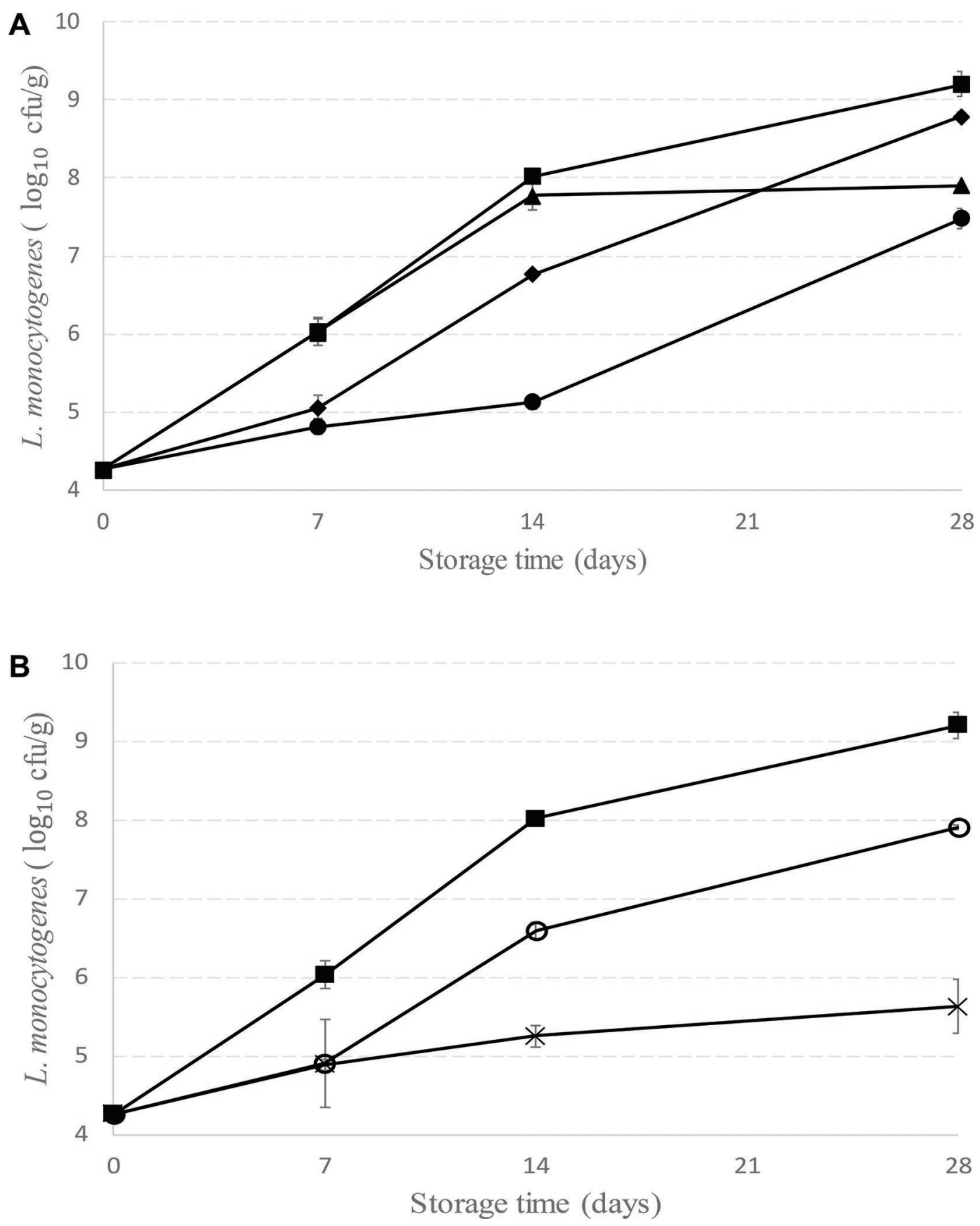

Figure 1. Effect of generally recognized as safe antimicrobials on Listeria monocytogenes survival in queso fresco (QF) during storage at $4^{\circ} \mathrm{C}$. (A) Antimicrobials evaluated alone; (B) antimicrobials evaluated in combinations. (ロ) No antimicrobial; ( $)$ nisin (NIS): $250 \mu \mathrm{g} / \mathrm{g}$ nisin; $(\mathbf{\Delta})$ lauric arginate (LAE): $200 \mu \mathrm{g} / \mathrm{g}$ lauric arginate; $(\bullet) \varepsilon$-polylysine $(\mathrm{EPL}): 250 \mu \mathrm{g} / \mathrm{g} \varepsilon$-polylysine, (O) NIS-LAE: $250 \mu \mathrm{g} / \mathrm{g}$ nisin $+200 \mu \mathrm{g} / \mathrm{g}$ lauric arginate; $(\times)$ EPL-LAE: $250 \mu \mathrm{g} / \mathrm{g} \varepsilon$-polylysine $+200 \mu \mathrm{g} / \mathrm{g}$ lauric arginate. Values are means \pm SEM.

full concentration of both antimicrobials was observed (Figure 2a). However, after $28 \mathrm{~d}$ of storage, comparable L. monocytogenes counts were observed between EPL$\mathrm{LAE}$ at full concentrations and in all QF treatments with decreased LAE concentration; this means a final L. monocytogenes population of approximately $6 \log _{10}$ $\mathrm{cfu} / \mathrm{g}$ (Figure 2b).

\section{Susceptibility Assessment of QF L. Monocytogenes Isolates to EPL and LAE}

The susceptibility of L. monocytogenes cocktail isolates from selected treatments tested in QF (EPL, LAE, and EPL-LAE) was evaluated by determining the MIC of EPL and LAE at the end to the storage. After anti- 

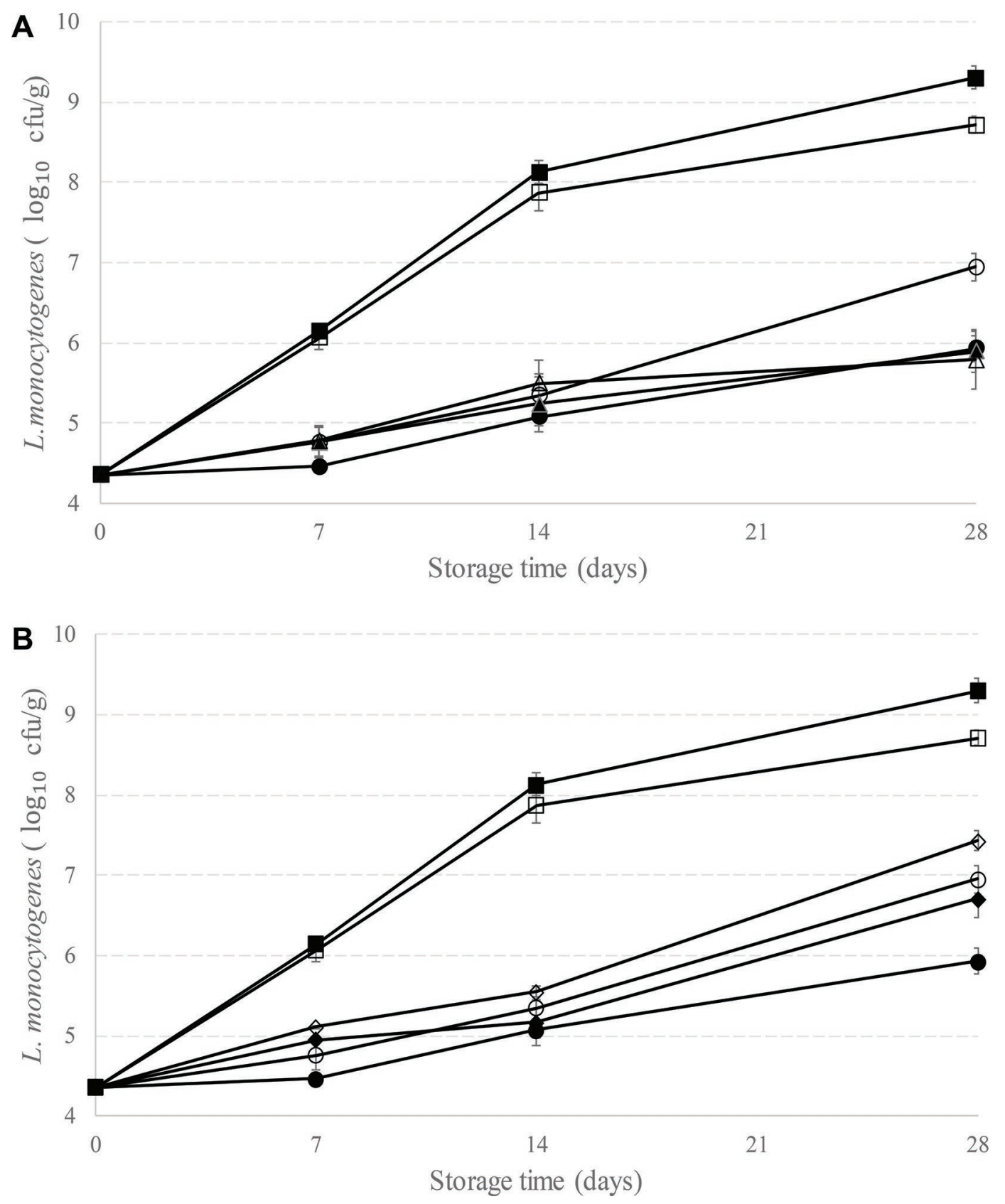

Figure 2. Effect of different concentrations of $\varepsilon$-polylysine (EPL)-lauric arginate (LAE) on Listeria monocytogenes survival in queso fresco (QF) during storage at $4^{\circ} \mathrm{C}$. (A) Reduced EPL concentrations; (B) reduced LAE concentrations. (ם) No antimicrobial; $(O)$ EPL $(250 \mu \mathrm{g} / \mathrm{g}$ ); (口) LAE $(200 \mu \mathrm{g} / \mathrm{g}) ;(\bullet)$ EPL $(250 \mu \mathrm{g} / \mathrm{g})+\mathrm{LAE}(200 \mu \mathrm{g} / \mathrm{g}) ;(\boldsymbol{\Lambda}) \mathrm{EPL}(250 \mu \mathrm{g} / \mathrm{g})+\mathrm{LAE}(133.33 \mu \mathrm{g} / \mathrm{g}) ;(\Delta)$ EPL $(250 \mu \mathrm{g} / \mathrm{g})+\mathrm{LAE}(66.66$

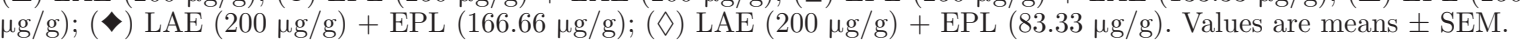

microbial exposure in QF during cold storage over $28 \mathrm{~d}$, susceptibility to EPL and LAE of Listeria isolates from QF samples treated with EPL $(250 \mu \mathrm{g} / \mathrm{mL})$, LAE $(200$ $\mu \mathrm{g} / \mathrm{mL})$, and EPL $(250 \mu \mathrm{g} / \mathrm{mL})+\mathrm{LAE}(200 \mu \mathrm{g} / \mathrm{mL})$ was similar compared with the susceptibility ranges of L. monocytogenes isolates from untreated cheeses $(P>$ 0.05, ANOM; Table 5).

\section{Sensory Evaluation: Triangle Test}

The QF added with EPL-LAE (QFT: $250 \mu \mathrm{g} / \mathrm{g}$ EPL $+66.66 \mu \mathrm{g} / \mathrm{g} \mathrm{LAE}$ ) and without antimicrobials (QFC) were produced and stored for up to $15 \mathrm{~d}$ at $4^{\circ} \mathrm{C}$ for their sensory evaluation. At d 1, 27 out of the 64 assessors correctly distinguished the samples in the test; this 
Table 5. Antimicrobial susceptibility of Listeria monocytogenes isolates $^{1,2}$ to $\varepsilon$-polylysine (EPL) and lauric arginate (LAE) after $28 \mathrm{~d}$ of storage in queso fresco $(\mathrm{QF})$ at $4^{\circ} \mathrm{C}$

\begin{tabular}{lcc}
\hline QF treatment & $\begin{array}{c}\text { LAE MIC } \\
(\mu \mathrm{g} / \mathrm{mL})\end{array}$ & $\begin{array}{c}\text { EPL MIC } \\
(\mu \mathrm{g} / \mathrm{mL})\end{array}$ \\
\hline No antimicrobial & 12.5 & $125-250$ \\
LAE & 12.5 & $\mathrm{NT}^{3}$ \\
EPL & $\mathrm{NT}$ & $125-250$ \\
LAE-EPL & 12.5 & $125-250$ \\
\hline
\end{tabular}

${ }^{1}$ Three random L. monocytogenes isolates per cheese treatment per independent experiment $(\mathrm{n}=36)$.

${ }^{2}$ No significant differences with the overall antimicrobial susceptibility in the population by analysis of means $(P>0.05)$.

${ }^{3} \mathrm{NT}=$ not tested.

represented a calculated population proportion $(\% P)$ of $25 \%$ that could distinguish the 2 samples, indicating that QFT is different than QFC (limit was set at 20\%). At d 15 of cold storage (second triangle test), a total of 33 out of the 64 assessors correctly identified the samples in the test, which represented $39 \%$ of the population proportion that could distinguish the 2 samples, indicating again that QFT is different than QFC. Despite the similar outcome in both triangle tests, different sensory observations from each triangle test were obtained. Assessors reported differences in texture and saltiness at d 1, indicating that QFT was drier and more salty, whereas they perceived differences in taste at d 15, reporting that QFT had a bitter taste.

\section{DISCUSSION}

Listeria monocytogenes contamination continues to be a public health concern, often being linked to Hispanic-style cheeses such as QF. Despite efforts to reduce the incidence of $L$. monocytogenes in $\mathrm{QF}$, most antimicrobial interventions have not eliminated or controlled the pathogen in QF. In our study, we aimed to evaluate combinations of commercially available antimicrobials: NIS, LAE, and EPL, as a hurdle approach to improve QF safety.

\section{Determination of MIC and Interactions Between GRAS Antimicrobials in Broth}

The MIC was determined for each GRAS antimicrobial used in this work (Table 3). Similar sensitivity among all Listeria strains tested for LAE and EPL was observed; however, L. monocytogenes strains tested were more susceptible to NIS than L. innocua. Overall, GRAS antimicrobials evaluated showed different antilisterial activity: NIS displayed the lowest MIC (3.12 $\mu \mathrm{g} / \mathrm{g})$ against Listeria, whereas EPL had the highest MIC $(125 \mu \mathrm{g} / \mathrm{g})$. Nisin is known to be effective against gram-positive bacteria, such as Listeria, whereas LAE and EPL have shown inhibitory effects against both gram-positive and gram-negative bacteria (Techathuvanan et al., 2014; Kozak et al., 2017; Ma et al., 2020), but studies have reported less efficacy of EPL against Listeria (Geornaras et al., 2007).

To explore the potential synergy between NIS, ELP, and LAE, binary combinations of the antimicrobials were tested in vitro. When LAE was combined with either NIS or EPL by the checkerboard method, a synergistic effect was observed, whereas the combination of NIS with EPL resulted in the indifference effect (Table 4). Other studies have reported similar results for binary combinations of NIS, EPL, and LAE against Listeria in broth (Najjar et al., 2007; Brandt et al., 2010; Kozak et al., 2017). The EPL and NIS are both cationic antimicrobials requiring interaction with the anionic phospholipids in the cell wall to exert their antimicrobial action (Lin et al., 2018; Ibarra-Sánchez et al., 2020). The LAE is a cationic surfactant that damages bacterial cell membranes and may also act lethally in the intracellular environment (Ma et al., 2020). This suggest that the lack of synergistic effect between EPL and NIS against Listeria in broth may be due to competition for the same target (cell wall phospholipids), whereas the synergy of LAE with either EPL or NIS may be due in part of LAE having different target (cell membranes) for their antilisterial activity. Our results suggest that combinations of NIS-LAE and EPL-LAE may display enhanced antilisterial control in a food matrix like $\mathrm{QF}$.

\section{Evaluation of Binary Combinations of Antimicrobials in QF}

Our results showed limited efficacy of NIS and LAE alone when added into QF to control L. monocytogenes growth. We have shown in our previous studies the inability of nisin to inhibit Listeria in QF (Van Tassell et al., 2015; Ibarra-Sánchez et al., 2018; Feng et al., 2019), and Soni et al. (2010, 2012) have demonstrated antilisterial limitations for LAE in QF. Kozak et al. (2018) reported that EPL was ineffective to inhibit $L$. monocytogenes growth in $\mathrm{QF}$ stored at $7{ }^{\circ} \mathrm{C}$; however, our results showed that EPL was effective to limit the growth of the pathogen in $\mathrm{QF}$ for 2 wk of storage at $4^{\circ} \mathrm{C}$. Despite NIS and LAE displaying greater antilisterial activity in vitro (Table 3 ), both antimicrobials have reduced antilisterial activity in the QF matrix: NIS is unstable at near neutral $\mathrm{pH}$ and interacts with milk fat, caseins, and cations (Ibarra-Sánchez et al., 2020), and LAE can bind ionically to anionic food components (e.g., caseins) and also interact with fat (Sharma et al., 2013; Ma et al., 2020). Antimicrobial activity of EPL 
can also be reduced in the presence of anionic proteins due to EPL cationic nature (Tuersuntuoheti et al., 2019), but our results suggests that EPL is more stable in QF relative to NIS and LAE. The loss of antilisterial activity of EPL after $14 \mathrm{~d}$ of refrigerated storage may be due to hydrolysis of EPL by proteases from EPLtolerant microorganisms (Kito et al., 2002), which may also be present in the cheese microbiota.

Combining antimicrobials may help to improve the individual antimicrobial efficacy in the food matrix (David et al., 2013). In the present study, we selected binary combinations of antimicrobials that showed synergy in vitro to be evaluated in QF: NIS-LAE and EPL-LAE (Table 4). Contrary to the checkerboard results, the combination of NIS-LAE did not show antilisterial enhancement in QF compared with cheeses treated with only NIS or LAE. It is possible that the lack of antilisterial improvement of NIS-LAE combination may be due to both antimicrobials having stability limitations in the QF matrix as discussed above. When QF was treated with EPL-LAE combination, extended listeristatic was observed over $28 \mathrm{~d}$ of storage at $4^{\circ} \mathrm{C}$, whereas EPL alone controlled Listeria growth in QF for up to $14 \mathrm{~d}$. This is different from a previous study in which EPL-LAE combination was able to control L. monocytogenes growth in $\mathrm{QF}$ only for $7 \mathrm{~d}$ at $7^{\circ} \mathrm{C}$ (Kozak et al., 2018). Antilisterial improvement in the EPL-LAE combination may be in part the result of their combined antimicrobial action: EPL disruption of the cell wall could increase the penetration of LAE to damage the cytoplasmic membrane, which may require lower amounts of both antimicrobials to kill L. monocytogenes in QF. Although EPL-LAE combination was not sufficient to eliminate L. monocytogenes in $\mathrm{QF}$, the listeristatic effect of this antimicrobial mixture could be used to complement other physical treatments with listericidal (bactericidal to Listeria) effect, such as highpressure processing (HPP), for an effective antilisterial intervention in QF: HPP can reduce L. monocytogenes population in the cheese (Tomasula et al., 2014) and then EPL-LAE treatment helps to prevent regrowth of the pathogen (either from HPP survivors or consumer contamination).

To explore if the combination of EPL-LAE may have optimization potential, the antimicrobial mixture was evaluated by reducing the concentration of one of the antimicrobials while maintaining the maximum permitted concentration of the second (Table 2). Our results showed that QF treatments in which EPL concentration was reduced, the antilisterial efficacy decreased (Figure 2a). However, in cheeses in which LAE concentration was reduced instead, the extended listeristatic effect was comparable to the EPL-LAE treatment with the maximum antimicrobial concentrations (Figure 2b).
Our results suggest that the antilisterial efficacy of EPL-LAE is dependent on EPL concentration and that small amounts of LAE may compensate for the possible loss or degradation of EPL in QF during cold storage. Additionally, the reduction of LAE concentration lowers the cost of the EPL-LAE antimicrobial treatment for QF processors.

The use of multiple antimicrobials can also limit the potential development of antimicrobial-resistant foodborne pathogens in the food (Bollenbach, 2015). In the present study, no significant changes in susceptibility to either EPL or LAE were observed in $36 \mathrm{~L}$. monocytogenes isolates recovered from $12 \mathrm{QF}$ samples, regardless of antimicrobials being added individually or in combination at their maximum permitted concentrations (LAE: $200 \mu \mathrm{g} / \mathrm{g}$, EPL: $250 \mu \mathrm{g} / \mathrm{g}$ ). This suggests that regrowth of L. monocytogenes in QF added with either LAE or EPL may be associated with instability or degradation of the antimicrobials in the cheese matrix during storage, rather than development of antimicrobial resistance by L. monocytogenes.

\section{Sensory Evaluation: Triangle Test}

It has been reported that both EPL and LAE have a bitter taste when either antimicrobial is added to foods in large amounts (Hyldgaard et al., 2014; Ma et al., 2020). Although LAE has shown negligible effect on QF sensory properties (Soni et al., 2010), the use of a mixture of 2 antimicrobials with bitter taste (EPL-LAE combination) may affect the subtle flavor of QF. We tested the EPL-LAE combination at the lowest concentration that showed antilisterial inhibition in QF (250 $\mu \mathrm{g} / \mathrm{g} \mathrm{EPL}+66.66 \mu \mathrm{g} / \mathrm{g} \mathrm{LAE})$. At d 1 and 15 of cheese storage, a significant proportion of assessors identified differences between QF samples with (QFT) and without (QFC) the antimicrobial treatment. However, an assessor identified the odd sample (QFT) at d 1 due to its drier texture and salty taste relative to control QF, but no assessor reported a bitter taste, suggesting that EPL-LAE was not detected at the concentrations added to QF. This result can be attributed to the extra manipulation of the dried curd during the addition of the EPL-LAE mixture during the cheesemaking process, releasing more whey and concentrating the salt in curd. At the second triangle test (d 15), assessors perceived a bitter taste in QFT samples, suggesting the accumulation of bitter compounds in the cheese. The bitter taste development in QFT may be a consequence of the antimicrobial activity of EPL-LAE in the cheese: both antimicrobials cause the release of intracellular proteases or peptidases from microorganisms of QF microbiota, promoting proteolysis of casein an even EPL, resulting in accumulation of bitter peptides. However, 
additional experiments are needed to determine the effect of EPL-LAE on bitter taste development in QF.

\section{CONCLUSIONS}

The present study evaluated the potential efficacy of NIS, LAE, and EPL in combinations to inhibit $L$. monocytogenes in QF. Combinations of NIS-LAE and EPL-LAE were synergistic in vitro. However, only EPL-LAE combination was effective to control $L$. monocytogenes in $\mathrm{QF}$, allowing up to $\sim 1.5 \log _{10} \mathrm{cfu} / \mathrm{g}$ pathogen growth over $28 \mathrm{~d}$ at $4^{\circ} \mathrm{C}$. Listeristatic effect of EPL-LAE in QF was maintained even after reduction of LAE concentration in the antimicrobial combination, indicating optimization potential. Additionally, $L$. monocytogenes did not develop resistance to either EPL or LAE in QF. The addition of the partially optimized EPL-LAE treatment may have affected QF sensory properties, especially when QF was stored for $15 \mathrm{~d}$ at $4^{\circ} \mathrm{C}$. Future work could focus on optimizing the concentrations of EPL and LAE when combined, including alternatives for their addition during cheesemaking and complementing the EPL-LAE mixture with listericidal physical treatments, and also exploring combinations of EPL with other novel natural antimicrobials and their evaluation in QF under cold-abuse temperature conditions. However, the findings in this work supports the use of EPL and LAE as a hurdle approach to control $L$. monocytogenes growth over the shelf life of QF.

\section{ACKNOWLEDGMENTS}

The authors thank Posgrado de Alimentos de la Facultad de Química of the Universidad Autónoma de Querétaro (Querétaro, México) and the University of Illinois at Urbana-Champaign (Urbana, IL) for the facilities provided to conduct the present research. This study was supported by the USDA Cooperative State Research, Education and Extension Service (Washington, DC) Hatch project no. ILLU-698-339 to MJM, Universidad Autónoma de Querétaro-University of Illinois Small Research Grants Program, and CONACyT (National Council of Science and Technology, México) for the MS scholarship to ARMR and PhD scholarship to LAIS. The authors have not stated any conflicts of interest.

\section{REFERENCES}

Becerril, R., S. Manso, C. Nerin, and R. Gómez-Lus. 2013. Antimicrobial activity of Lauroyl Arginate Ethyl (LAE), against selected food-borne bacteria. Food Control 32:404-408. https://doi.org/10 .1016/j.foodcont.2013.01.003.
Bollenbach, T. 2015. Antimicrobial interactions: Mechanisms and implications for drug discovery and resistance evolution. Curr. Opin. Microbiol. 27:1-9. https://doi.org/10.1016/j.mib.2015.05.008.

Brandt, A. L., A. Castillo, K. B. Harris, J. T. Keeton, M. D. Hardin, and T. M. Taylor. 2010. Inhibition of Listeria monocytogenes by food antimicrobials applied singly and in combination. J. Food Sci. 75:M557-M563. https://doi.org/10.1111/j.1750-3841.2010 .01843.x.

CDC-NORS. 2018. National Outbreak Reporting System (NORS). Accessed May 12, 2020. https://wwwn.cdc.gov/norsdashboard/.

David, J. R. D., L. R. Steenson, and P. M. Davidson. 2013. Expectations and applications of natural antimicrobials to foods: A guidance document for users, suppliers, research and development, and regulatory agencies. Food Prot. Trends 33:238-247.

FDA. 2004. Agency Response Letter GRAS Notice No. GRN000135. Accessed May 12, 2020. http://wayback.archive-it.org/7993/ 20171031053057/https:/ / www.fda.gov/downloads/Food/ Ingredients PackagingLabeling/GRAS / NoticeInventory / UCM267372.pdf.

FDA. 2005. Agency Response Letter GRAS Notice No. GRN 000164. Accessed May 12, 2020. http://wayback.archive-it .org/7993/20171031052522/https://www.fda.gov/downloads/ Food/IngredientsPackagingLabeling/GRAS/NoticeInventory/ UCM268847.pdf.

Feng, Y., L. A. Ibarra-Sánchez, L. Luu, M. J. Miller, and Y. Lee. 2019. Co-assembly of nisin and zein in microfluidics for enhanced antilisterial activity in queso fresco. Lebensm. Wiss. Technol. 111:355362. https://doi.org/10.1016/j.lwt.2019.05.059.

Gadotti, C., F. Forghani, and F. Diez-Gonzalez. 2020. Evaluation of single and combined antimicrobial treatments to inhibit Salmonella in queso fresco. Food Microbiol. 85:103286. https://doi.org/ 10.1016/j.fm.2019.103286.

Gadotti, C., L. Nelson, and F. Diez-Gonzalez. 2014. Inhibitory effect of combinations of caprylic acid and nisin on Listeria monocytogenes in queso fresco. Food Microbiol. 39:1-6. https://doi.org/10.1016/ j.fm.2013.10.007.

García, L. 2010. Synergism testing: Broth microdilution checkerboard and broth macrodilution methods. Pages 140-162 in Clinical Microbiology Procedures Handbook. 3rd ed. ASM Press, Washington, DC. https://doi.org/10.1128/9781555817435.ch5.12.

Geornaras, I., Y. Yoon, K. E. Belk, G. C. Smith, and J. N. Sofos. 2007. Antimicrobial activity of $\varepsilon$-polylysine against Escherichia coli O157:H7, Salmonella Typhimurium, and Listeria monocytogenes in various food extracts. J. Food Sci. 72:M330-M334. https: //doi.org/10.1111/j.1750-3841.2007.00510.x.

Hawkins, D. R., X. Rocabayera, S. Ruckman, R. Segret, and D. Shaw. 2009. Metabolism and pharmacokinetics of ethyl No-lauroyl-Larginate hydrochloride in human volunteers. Food Chem. Toxicol. 47:2711-2715. https://doi.org/10.1016/j.fct.2009.07.028.

Hiraki, J., T. Ichikawa, S. Ninomiya, H. Seki, K. Uohama, H. Seki, S. Kimura, Y. Yanagimoto, and J. W. Barnett Jr.. 2003. Use of ADME studies to confirm the safety of $\varepsilon$-polylysine as a preservative in food. Regul. Toxicol. Pharmacol. 37:328-340. https://doi .org/10.1016/S0273-2300(03)00029-1.

Hoffmann, S., M. B. Batz, and J. G. Morris Jr.. 2012. Annual cost of illness and quality-adjusted life year losses in the United States due to 14 foodborne pathogens. J. Food Prot. 75:1292-1302. https: //doi.org/10.4315/0362-028X.JFP-11-417.

Hyldgaard, M., T. Mygind, B. S. Vad, M. Stenvang, D. E. Otzen, and R. L. Meyer. 2014. The antimicrobial mechanism of action of epsilon-poly-L-lysine. Appl. Environ. Microbiol. 80:7758-7770. https://doi.org/10.1128/AEM.02204-14.

Ibarra-Sánchez, L. A., N. El-Haddad, D. Mahmoud, M. J. Miller, and L. Karam. 2020. Invited review: Advances in nisin use for preservation of dairy products. J. Dairy Sci. 103:2041-2052. https://doi .org/10.3168/jds.2019-17498.

Ibarra-Sánchez, L. A., M. Van Tassell, and M. J. Miller. 2017. Invited review: Hispanic-style cheeses and their association with Listeria monocytogenes. J. Dairy Sci. 100:2421-2432. https://doi.org/10 $.3168 /$ jds.2016-12116. 
Ibarra-Sánchez, L. A., M. L. Van Tassell, and M. J. Miller. 2018. Antimicrobial behavior of phage endolysin PlyP100 and its synergy with nisin to control Listeria monocytogenes in queso fresco. Food Microbiol. 72:128-134. https://doi.org/10.1016/j.fm.2017.11.013.

ISO 4120. 2004. Sensory analysis. Methodology. Triangle test. International Organization for Standardization, Geneva, Switzerland.

Kito, M., Y. Onji, T. Yoshida, and T. Nagasawa. 2002. Occurrence of O-poly-L-lysine-degrading enzyme in O-poly-L-lysine-tolerant Sphingobacterium multivorum OJ10: Purification and characterization. FEMS Microbiol. Letters 207:147-151.

Kozak, S. M., Y. Bobak, and D. J. D'Amico. 2018. Efficacy of antimicrobials applied individually and in combination for controlling Listeria monocytogenes as surface contaminants on queso fresco. J. Food Prot. 81:46-53. https://doi.org/10.4315/0362-028X.JFP $-17-279$.

Kozak, S. M., K. M. Margison, and D. J. D'amico. 2017. Synergistic antimicrobial combinations inhibit and inactivate Listeria monocytogenes in neutral and acidic broth systems. J. Food Prot. 80:1266-1272. https://doi.org/10.4315/0362-028X.JFP-17-035.

Lin, L., Y. Gu, C. Li, S. Vittayapadung, and H. Cui. 2018. Antibacterial mechanism of $\varepsilon$-Poly-lysine against Listeria monocytogenes and its application on cheese. Food Control 91:76-84. https://doi .org/10.1016/j.foodcont.2018.03.025.

Liu, W., and J. N. Hansen. 1990. Some chemical and physical properties of nisin, a small-protein antibiotic produced by Lactococcus lactis. Appl. Environ. Microbiol. 56:2551-2558. https://doi.org/10 .1128/AEM.56.8.2551-2558.1990.

Lourenço, A., M. B. Kamnetz, C. Gadotti, and F. Diez-Gonzalez. 2017. Antimicrobial treatments to control Listeria monocytogenes in queso fresco. Food Microbiol. 64:47-55. https://doi.org/10 $.1016 /$ j.fm.2016.12.014.

Ma, Q., P. M. Davidson, and Q. Zhong. 2020. Properties and potential food applications of lauric arginate as a cationic antimicrobial. Int. J. Food Microbiol. 315:108417. https://doi.org/10.1016/ j.ijfoodmicro.2019.108417.

Najjar, M. B., D. Kashtanov, and M. L. Chikindas. 2007. ع-Poly-Llysine and nisin A act synergistically against Gram-positive foodborne pathogens Bacillus cereus and Listeria monocytogenes. Lett. Appl. Microbiol. 45:13-18. https://doi.org/10.1111/j.1472-765X 2007.02157.x.

Sharma, C. S., A. Ates, P. Joseph, K. A. Soni, M. W. Schilling, and A. Kiess. 2013. Evaluation of antimicrobial effects of lauric arginate on reduction of Salmonella spp. in ground chicken. Int. J. Food Sci. Technol. 48:1410-1415. https://doi.org/10.1111/ijfs.12103.

Soni, K. A., M. Desai, A. Oladunjoye, F. Skrobot, and R. Nannapaneni. 2012. Reduction of Listeria monocytogenes in queso fresco cheese by a combination of listericidal and listeriostatic GRAS antimicrobials. Int. J. Food Microbiol. 155:82-88. https://doi.org/ 10.1016/j.ijfoodmicro.2012.01.010.

Soni, K. A., R. Nannapaneni, M. W. Schilling, and V. Jackson. 2010. Bactericidal activity of lauric arginate in milk and queso fresco cheese against Listeria monocytogenes cold growth. J. Dairy Sci. 93:4518-4525. https://doi.org/10.3168/jds.2010-3270.

Techathuvanan, C., F. Reyes, J. R. D. David, and P. M. Davidson. 2014. Efficacy of commercial natural antimicrobials alone and in combinations against pathogenic and spoilage microorganisms. J. Food Prot. 77:269-275. https://doi.org/10.4315/0362-028X.JFP $-13-288$.

Tomasula, P. M., J. A. Renye, D. L. Van Hekken, M. H. Tunick, R. Kwoczak, M. Toht, L. N. Leggett, J. B. Luchansky, A. C. S. PortoFett, and J. G. Phillips. 2014. Effect of high-pressure processing on reduction of Listeria monocytogenes in packaged queso fresco. J. Dairy Sci. 97:1281-1295. https://doi.org/10.3168/jds.2013-7538.

Tuersuntuoheti, T., Z. Wang, Z. Wang, S. Liang, X. Li, and M. Zhang. 2019. Review of the application of $\varepsilon$-poly-L-lysine in improving food quality and preservation. J. Food Process. Preserv. 43:1-14. https://doi.org/10.1111/jfpp.14153.

U.S. Department of Agriculture, Economic Research Service (USDA ERS). 2014. Cost of foodborne illness estimates for Listeria monocytogenes. Accessed Jul. 22, 2020. http://www.ers.usda.gov/data -products/cost-estimates-of-foodborne-illnesses.aspx\#48443.

Van Tassell, M. L., L. A. Ibarra-Sánchez, S. R. Takhar, S. L. AmayaLlano, and M. J. Miller. 2015. Use of a miniature laboratory fresh cheese model for investigating antimicrobial activities. J. Dairy Sci. 98:8515-8524. https://doi.org/10.3168/jds.2015-9967.

\section{ORCIDS}

Alma R. Martínez-Ramos @ https://orcid.org/0000-0003-0171-9191 Luis A. Ibarra-Sánchez @ https://orcid.org/0000-0001-7023-218X Silvia L. Amaya-Llano ㄴ) https://orcid.org/0000-0001-8236-0357

Michael J. Miller @ https://orcid.org/0000-0001-8579-1080 